\title{
Controle social E NeCESSIDAde de PROTeÇÃo de dAdOS PeSSOAIS
}

\author{
Social control and the protection of personal data
}

\section{José Renato Gaziero Cella}

Doutor em Filosofia e Teoria do Direito pela Universidade Federal de Santa Catarina - UFSC, Mestre em Direito do Estado pela Universidade Federal do Paraná - UFPR, Professor do Programa de Pós-Graduação (Mestrado) em Direito da Faculdade Meridional - IMED e do Curso de Graduação em Direito da Pontifícia Universidade Católica do Paraná - PUCPR. E-mail: cella@cella.com.br.

\section{Luana Aparecida dos Santos Rosa}

Graduanda em Filosofia da Universidade Federal do Paraná - UFPR e em Direito da Pontifícia Universidade Católica do Paraná - PUCPR, pesquisadora de iniciação científica PIBIC/CNPq. E-mail: luanacorderosa@hotmail.com.

RECEBIDO EM: 01.07.2013

APROVADO EM: 20.08.2013

\section{RESUMO}

Há muito se tem tratado a ideia de sociedade disciplinar e sociedade de controle, consagradas, por exemplo, nas obras de Michel Foucault e Gilles Deleuze. A contemporaneidade trouxe inúmeros desdobramentos em relação aos conceitos atribuídos por Foucault e Deleuze, sendo que muitos desses resultados foram previstos pela análise de acontecimentos por esses pensadores; entretanto continua-se em busca do entendimento da evolução das sociedades no que tange ao poder e a sua manutenção, ao direito, à ética e aos possíveis resultados sociais futuros. Faz-se necessário entender a dialeticidade desse tema para compreender o momento atual e pensar o futuro. O escopo deste artigo é entender o controle social e os desdobramentos do poder na denominada Sociedade da Informação, tanto na esfera pública quanto na esfera privada. O avanço da técnica, com o surgimento da internet, é significativo na história das comunicações em termos de agilidade e rapidez. À luz dos marcos teóricos eleitos para o desenvolvimento deste artigo, o controle se estabelece pela ideia de necessidade relativamente ao veículo de informação, em que a sociedade de controle é a sucessora do paradigma disciplinar (a disciplina já está incorporada). Para Deleuze, a vigilância e a monitoração são formas de atuação do controle, ou seja, a reinvenção do panóptico de Jeremy Bentham. As ramificações 
dessa forma de sociedade se valem da internet e seu acesso facilitado para se propagar ao maior contingente de pessoas possível, seja por meio de redes sociais, programas de reality-shows, inclusão de câmeras de vigilância, exatamente como se referia George Orwell na obra 1984. Pretende-se analisar se a rapidez de informações supera a falta de segurança, haja vista que hoje se vê, por exemplo, casos como o dos Estados Unidos da América, que realizam a espionagem de indivíduos e de governos estrangeiros, o que torna necessário não só pensar o direito, mas também pensar se a legislação que existe é eficaz para a proteção dos dados pessoais.

Palavras-chave: Sociedade do conhecimento. Controle social. Proteção de DaDOS PESSOAIS.

\begin{abstract}
There has long been treated the idea of discipline society and control society, dealing, for example, the works of Michel Foucault and Gilles Deleuze. The contemporary brought numerous developments in relation to the concepts assigned by Foucault and Deleuze, and many of these results were predicted by the analysis of events by these thinkers, however we are still in search for understanding the evolution of societies in relation to power and its maintenance, Law, Ethics, and possible future social outcomes. It is necessary to understand the dialectics of this topic to understand the current situation and thinking about the future. The scope of this paper is to understand the social control and the ramifications of power called the Information Society, both in public and in the private sphere. The state of the art, with the advent of internet, it is significant in the history of communications in terms of speed and agility. In light of the theoretical framework chosen for the development of this paper, the control is established by the idea of discipline and the society of control is the successor to the disciplinary paradigm (the discipline is already incorporated). For Deleuze, surveillance and monitoring activities are forms of control, ie, the reinvention of Jeremy Bentham's panopticon. The ramifications of this form of society make use of the internet and its easy access to propagate the largest number of people possible, whether through social networking programs, reality shows, including surveillance cameras, just like George Orwell referred in his book 1984. Intend to analyze the information quickly overcomes the lack of security, given that it is today, for example, cases such as the United States, who perform espionage individuals and foreign governments, which makes it necessary not think only the right but also wonder if there is effective legislation for the protection of personal data.
\end{abstract}

Keywords: Knowledge society. Social control. Protection of personal data. 
Sumário: 1. Sociedade do conhecimento e tecnologia. 2. Da possibilidade de controle social pela internet. 3. As redes rociais e a WEB 2.0. 4. Os EUA e o controle social. Conclusão. Referências.

\section{INTRODUÇÃo}

Como toda revolução nas comunicações, a internet produziu uma série de efeitos inesperados com os quais sociedades e governos precisam lidar. Por vezes, não existem nem mesmo instrumentos jurídicos para tratar das novas realidades. Muito já foi escrito em relação ao avanço da tecnologia e a forma de aplicação da técnica. Desde as revoluções industriais, a palavra evolucionismo para o homem médio pode significar, entre outras acepções, avanço tecnológico. Atualmente há a obrigatoriedade das coisas andarem mais rápido. É uma exigência do mundo contemporâneo, pois quanto mais depressa o sujeito trabalhar, estudar e, ainda, obter os melhores resultados possíveis, será considerado atualizado, ambientado, enturmado. Enfim, parece que a Terra gira mais rápido.

$\mathrm{O}$ avanço da técnica, com o surgimento da internet, é significativo na história das comunicações em termos de agilidade e rapidez, haja vista que as notícias sobre os acontecimentos percorrem o mundo em apenas segundos, sem controle de conteúdo. A possibilidade de acesso à internet repercute na exigência de rapidez. Por exemplo, há pouco tempo os trabalhos escolares e acadêmicos eram feitos mediante consultas às enciclopédias etc., sendo que em uma década os livros deixaram de ser consultados e começou a ser usado o Google como meio de consulta, ou seja, as pesquisas que duravam horas foram substituídas por apenas um clique. $\mathrm{O}$ uso da internet trouxe inúmeros benefícios, mas resta saber se tem sido utilizado de forma segura e consciente, como uma das fontes de acesso, mas não como fonte exclusiva de acesso à informação.

Essa evolução culminou no surgimento da denominada sociedade de conhecimento. É preciso compreender os desdobramentos jurídicos dessa forma de comunicação, a internet.

É nesse contexto que o governo brasileiro apresentou seu projeto de marco regulatório civil para a rede. A proposta, que foi a consulta pública antes de ser encaminhada para o Congresso Nacional, esteve disponível no sítio eletrônico http:// culturadigital.br/marcocivil/, em que se pode consultar os resultados dos debates.

$\mathrm{O}$ debate permitiu que se eliminassem os excessos que marcaram o polêmico projeto de legislação penal para a internet - apelidado de Lei Azeredo - que tramita no Poder Legislativo brasileiro.

Em suas versões iniciais, o substitutivo do então senador Azeredo previa que cada internauta se cadastrasse antes de se conectar na rede e exigia que os prove- 
dores atuassem como policiais, com monitoramento dos passos cibernéticos de seus clientes e com sua delação diante da menor suspeita de abuso. Essas ideias acabaram ceifadas da proposta.

Diante disso, a preocupação que se tem é com o Marco Civil regulatório da internet no Brasil, sobretudo no que tange ao armazenamento de dados que se pretende que os provedores da internet façam relativamente a seus clientes.

Consideradas as legislações específicas sobre o assunto, em termos de segurança de dados, com a facilitação da internet, ainda se estudam as sanções e limitações jurídicas. $\mathrm{O}$ direito brasileiro tem-se adequado à agilidade permitida pelo meio eletrônico em busca, por exemplo, da celeridade processual relativamente a implementação do processo eletrônico.

Cumpre analisar, sendo este o objeto do presente artigo, se as preocupações jurídicas têm dado a ênfase necessária ao tema da proteção de dados pessoais.

\section{SOCIEDADE DO CONHECIMENTO E TECNOLOGIA}

Há que se analisar se a rapidez de informações supera a falta de segurança, haja vista que há casos diários de crimes ou condutas ilícitas cometidas por meio da internet, muitas ainda sem previsão legal; é preciso estudar a regulação da internet, especificamente em relação a proteção de dados pessoais.

Semelhante tentativa de controle se deu quando da invenção dos tipos móveis por Johannes Gutenberg, em torno de 1455. Antes da imprensa o número de manuscritos em circulação na Europa se contava em milhares. Cinco décadas depois, em 1500, havia mais de 9 milhões de livros no Velho Continente. No início, foram impressas bíblias, hagiografias, livros de orações e material religioso. Logo, porém, vieram obras laicas e, pior, as consideradas subversivas.

Em 1559 a Igreja Católica emite o primeiro Index Librorum Prohibitorum (catálogo dos livros proibidos). A censura estava institucionalizada.

$\mathrm{O}$ contexto, entretanto, era o da Reforma e da Contrarreforma. O índex e as fronteiras não bastaram para evitar que livros considerados subversivos fossem impressos nas terras do adversário e voltassem contrabandeados a seu público-alvo.

Com a internet, em que basta um enter para navegar por terras estrangeiras, é impossível controlar ideias e o que o direito chama de delitos de opinião.

É preciso não só pensar o direito, mas também pensar se a legislação que existe é eficaz e se o pensamento incorporado na sociedade atual, a respeito do tema, dá suporte às necessidades sociais.

Um conceito hoje razoavelmente arraigado de técnica a considera, sumariamente, como o complexo de atos pelos quais os homens agem sobre a natureza, procurando aperfeiçoar instrumentos que os ajudem a satisfazer suas necessidades $^{236}$; atos esses reunidos e sistematizados pela tecnologia - o estado da técnica em

${ }^{236}$ Agostino Carrino. "Progresso e modernità", in: Il diritto nella società moderna. Agostino 
um determinado momento.

Assim entendida, a tecnologia apresenta um caráter fortemente instrumental e utilitarista. A tendência de convergir, nesses aspectos, a noção de tecnologia, pela qual ela é basicamente um meio para atingir um fim a ela exterior, é muito for$\mathrm{te}^{237}$. Por outro lado, existe o apelo de alguns autores para relativizar ou mesmo negar a sua pretensa neutralidade, que derivaria deste seu caráter instrumental.

Um conteúdo ideológico que negue essa sua pretensa neutralidade é algo que dificilmente se pode depreender diretamente da tecnologia, ao menos em uma primeira análise conceitual. Uma sociedade, no entanto, percorre os caminhos que lhe permitem as possibilidades técnicas de sua época, e é inegável, por exemplo, o fato de que o desenvolvimento do capitalismo moderno é tributário de uma tecnologia em constante evolução que lhe fornece ambiente propício ${ }^{238}$. Essa constatação é apenas um indício, embora importante, de que a noção de tecnologia não pertence a um universo alheio a uma determinada conjuntura político-social. Determinar qual é seu papel, porém, é tarefa árdua, e já levou o historiador Melvin Kranzberg a afirmar que "a tecnologia não é boa nem má, nem sequer é neutra" 239 - no que foi de certa forma acompanhado por Pierre Lévy ${ }^{240}$.

Um método que pode fazer permitir perceber o substrato ideológico presente na tecnologia é a sua consideração a partir do seu perfil dinâmico. Isso por que o seu perfil puramente estático relacionaria a tecnologia principalmente com seu aspecto utilitarista - o de ferramenta, instrumento para atingir um fim - o que, além de

Carrino (org.). Napoli: ESI, 1995, p. 203.

237 Tome-se, por exemplo, a concisa definição de "technology" no Merriam-Webster's Dictionary: "the practical application of knowledge especially in a particular area". O termo consta ter sido cunhado por Jacob Bigelow, professor em Harvard, por volta de 1820; suas raízes, porém, são muito mais antigas: em sua raiz, temos a palavra grega techne, que pode significar alternativamente arte ou habilidade, que por sua vez ecoa a influência da raiz indo-européia teks-, que corresponderia ao nosso verbo "fabricar", enquanto que por logia entende-se um tratamento sistemático, cf. Rudi Votti. Society and technological changes. New York: St. Martin's Press, 1988, p. 4.

238 "Ora il capitalismo occidentale specificatamente moderno evidentemente è condicionato in larga misura anche dallo svillupo di possibilità tecniche". Max Weber. L'etica protestante e lo spirito del capitalismo. Milano: Rizzoli, 1991, p. 45 [Ed. bras.: A Ética Protestante e o Espírito do Capitalismo. São Paulo: Pioneira Thomson Learning, 2001].

239 Manuel Castells. The rise of the network society. Blackwell: Oxford, 1996, p. 65 [Ed. bras.: A Sociedade em Rede. Rio de Janeiro: Paz e Terra, 1999] .

${ }^{240}$ Pierre Lévy referia-se, na verdade, à uma conseqüência da tecnologia: a "virtualização: "Or la virtualisation constitue justement l'essence, ou la fine pointe, de la mutation en cours. En tant que telle, la virtualisation n'est ni bonne, ni mauvaise, ni neutre. Elle se présente comme le mouvement même du 'devenir autre' - ou hétérogènese - de l'humain». (destaque nosso). Pierre Lévy. Qu’est-ce que le virtuel? Paris: La Découverte, 1998, p. 10 [Ed. bras.: O que é virtual? São Paulo: Editora 34, 1996]. 
neutralizar o discurso ideológico, foge à dimensão histórica intrínseca ao problema. Esse perfil dinâmico, pelo qual se pode observar precisamente o desenvolvimento tecnológico, é o ângulo de observação possível para abranger o máximo de seus efeitos e pôr em questão todos os seus aspectos relevantes, visto que a realimentação que a sociedade fornece à tecnologia depende também de juízos de valor.

Esse assim chamado perfil dinâmico da tecnologia dialoga diretamente com a noção de progresso e com toda a carga cultural que esse termo representa.

Hoje se verifica que a consciência do poder da técnica e de suas possibilidades como instrumento de mudança já era presente no Renascimento - basta fazer menção aos famosos projetos de Leonardo da Vinci e das suas máquinas de guerra que habitualmente oferecia aos Médici. Além da contribuição de Leonardo, muitos outros exemplos podem ser colhidos - talvez um dos mais fortes seja a importância da invenção da imprensa (a princípio por Gutemberg, por volta de 1461) ${ }^{241}$.

Tratar de tecnologia, portanto, não é a priori um exercício de futurologia, no entanto um olhar para o futuro está presente, inclusive na literatura científica. O desenvolvimento tecnológico na era pós-industrial ${ }^{242}$ é um fenômeno fortemente dinâmico, portanto o fato de que o pensamento filosófico e jurídico se ocupe das tendências e projeções para o futuro quando enfrenta temas relacionados com tecnologia é nada mais que coerente e necessário. E, assim procedendo, faz-se um cálculo

${ }^{241}$ Incerta, come si è detto, l'attribuzione della invenzione della stampa: la tradizione più accreditata è comunque quella che vuole in Johannes Gensfleish, detto Gutemberg, in primo in Occidente a realizzare un sistema pratico ed efficace per la fusione dei caratteri e per la loro impressione meccanica su carta, benché il suo nome non compaia nel colophon di alcun libro. Outros "candidatos" concorrem com seus nomes para que figurem na história como o inventor da imprensa, porém o que vale notar é que, como em outros casos, tal evento se deve menos à operosidade individual de pesquisadores isolados que à própria difusão do papel e de uma crescente necessidade de uma reprodução "mais rápida e menos dispendiosa" de escritos, o que a tecnologia da época já possibilitava. Marco Santoro. Storia del libro italiano. Milano: Bibliografica, 2000, pp. 41-46. A importância fundamental da imprensa para a difusão de idéias foi muito bem compreendida e utilizada por Lutero, que chegara a declarar que "la stampa è il più recente e il più grande regalo da Dio; così il Signore ha dimostrato volere divulgare la parola della vera religione in qualsiasi posto, fine all'ultima estremità del mondo, e diffonderla in tutte le lingue ". Mario Infelise. I libri proibiti. Bari: Laterza, 1999, p. 4.

${ }^{242}$ A "sociedade pós-industrial" foi descrita pelo sociólogo norte-americano Daniel Bell como sendo: "(...) one in which the majority of those employed are not involved in the production of tangible goods. The manual and unskilled worker class gets smaller and the class of knowledge workers becomes predominant. The character of knowledge also changes and an emphasis is put on theoretical knowledge rather than empirical". Daniel Bell, "Who will rule? Politicians and technocrats in the Post-Industrial Society", in: www.src.uchicago.edu/ ssr1/PRELIMS/Political/pomisc1.html (02/01/2004). A obra mais representativa do autor sobre o tema é The Coming of Post-Industrial Society. New York: Basic Books, 1999 (a edição original é de 1973). 
otimista $^{243}$, pessimista ${ }^{244}$ ou pretensamente realista em relação a essas tendências e projeções.

Hoje se pode contar com um mínimo de experiência nos confrontos de algumas utopias, positivas ou negativas, em comparação com a realidade atual. É possível propor um enfoque de cunho realístico na consideração das tendências e projeções tecnológicas, que devem ser analisadas e valoradas pelo homem em seu complexo de promessas e perigos. Assim, "sob esse aspecto, a era tecnológica revela a sua ambivalência e requer do homem algumas escolhas básicas que levem em conta suas possibilidades latentes, tanto para o bem quanto para o mal, para as gerações futuras" 245 .

O surgimento da rede internet, por exemplo, decididamente alargou as possibilidades de comunicação e suscitou a explosão de um grande número de questões ligadas à privacidade. $\mathrm{O}$ impacto que ela representa, porém, já estava em grande parte incubado em outras tecnologias anteriores, que provocaram fenômenos semelhantes e que, se hoje parecem pálidos, devem ser considerados em relação ao que representaram à sua época - algo que o suceder das gerações apaga da memória. Assim, o telégrafo e o telefone, como instrumentos de comunicação bidirecional, ou mesmo o rádio e a televisão, contribuíram cada um deles para formar a consciência de que representavam uma forma de encurtamento das distâncias ${ }^{246}$ e do fim de algumas limitações por ela causadas ${ }^{247} \mathrm{e}$, consequentemente, de uma interação mais frequente

${ }^{243}$ Como em Antonio E. Perez-Luño. Nuevas tecnologias, sociedade e derecho, Madrid, 1987.

${ }^{244}$ Lewis Mumford. The myth of the machine. New York: Harcourt, 1967. Também Denninger revela seu desalentado parecer: "Cosa c'è allora di nuovo nei nuovi diritti dell'età tecnologica? Forse la convinzione che il secolare disagio dell'uomo verso la giustizia non sarà risolto neanche dal progresso tecnico e scientifico. Se ne derivasse la coscienza di dover continuamente affrontare questi problemi in maniera responsabile, ciò sarebbe già molto". Erhard Denninger. "Tutela ed attuazione del diritto nell'età tecnologica", in: Nuovi diritti dell'età tecnologica, cit., p. 73.

245 Jerzy Wroblewski. “Dilemmi dell'età tecnologica: il diritto e l'omeostasi dell'esistenza umana”, in Nuovi diritti dell'età tecnologica. Francesco Riccobono (org.), Milano: Giuffrè, 1991, p. 197.

${ }^{246}$ A ideia da irrelevância das distâncias é uma constante na vasta literatura que procurou analisar o impacto das tecnologias de comunicação. v. Frances Cairncross. The death of distance. Boston: Harvard Press, 1997.

${ }^{247}$ Uma rápida coleta de algumas frases cunhadas na esteira da invenção e implementação do telégrafo, há século e meio, pode nos soar estranhamente familiar, tal ponto são semelhantes às exclamações ouvidas quando do surgimento da própria rede Internet. Vejamos algumas delas: "All the ends of the earth will be wooed into the electric telegraph circuit" (Scientific America, 1852); "All the inhabitants of the earth will be brought into one intellectual neighbourhood" (Alonzo Jackman, 1846); "The highway gridling the earth is found in the telegraph wires" (desconhecido, 1971). Um relato do impacto da invenção do telégrafo elétrico por Samuel Morse, William Cooke e Charles Wheatstone estão em: Tom Standage. The 
entre as pessoas, que está no âmago das questões relacionadas com privacidade.

A materialização mais facilmente visível dessa tendência é a própria internet, que é basicamente uma rede de computadores ${ }^{248}$ cuja estrutura prevê justamente a não dependência de centros de controle para sua operação, além de tornar difíceis as tentativas de controle do tráfego de dados, visto que consiste basicamente em um protocolo de comunicações, implementado em computadores, possibilitando sua interligação através dos vários meios de comunicação de dados existentes. Essa estrutura de rede é capaz de prescindir de caminhos únicos - podendo substituir eventuais vias de comunicação bloqueadas por outras - como consequência, não haveria mais elementos essenciais para seu funcionamento. Nessa disposição, um grande centro de processamento não é mais indispensável para a realização de um grande número de operações. O crescimento do poder de polos intermediários em detrimento de um controle central acabou por desenhar uma nova geografia da proteção de dados, na qual o poder encontra-se fracionado - o que fez com que a regulação então existente perdesse sua atualidade.

A rede internet recoloca em primeiro plano questões atinentes à relação da lei com o espaço - como na obra Il nomos della terra, de Carl Schmitt, a partir da qual se pode ler a proposta de Lawrence Lessig ${ }^{249}$. Na obra de Lessig se vê uma tentativa de compreender o meio no qual se processam boa parte das operações que hoje envolvem os dados pessoais - para o autor, o cyberspace. A proposição do problema nestes termos é, de certo modo, consequência lógica de um dos lugares comuns dessa temática: a afirmação de que a ineficiência inerente aos meios manuais de processamento de dados (arquivos cartáceos, máquinas de escrever etc.) constituíam-se em uma forma muito eficiente de proteção da privacidade até que sobreviessem os recentes avanços no processamento eletrônico de dados.

Por difícil que seja cristalizar a problemática da privacidade em um único conceito, é no entanto razoavelmente natural constatar que ela sempre foi diretamente condicionada pelo estado da tecnologia em cada época e sociedade. Pode-se inclusive aventar a hipótese de que o advento de estruturas jurídicas e sociais que tratem do problema da privacidade são respostas diretas a uma nova condição da informação, determinada pela tecnologia.

A possibilidade de comunicação é função direta da tecnologia disponível a esse fim. É perfeitamente congruente o fato de que as primeiras discussões, em sede jurídica ou não, sobre uma violação de privacidade com origem na divulgação de correspondência privada tenha se dado em sociedades que desenvolveram tecnologias que tornaram o correio um meio eficiente e ao alcance de um número

\footnotetext{
Victorian Internet. New York: Berkley Books, 1999.

${ }^{248}$ Andrew Tanembaum. Redes de computadores. Rio de Janeiro: Campus, 1997, p. 20.

${ }^{249}$ Neste caso, basicamente Code and other laws ..., cit. e "The architecture of privacy", in: Vanderbilt Entertainment Law and Practice, 1/1999, pp. 56-65.
} 
considerável de pessoas: desde o sistema elaborado pelos antigos romanos ${ }^{250}$, de cujos problemas advindos deixou registro Cícero; ao eficientíssimo sistema postal da Inglaterra vitoriana, cuja herança foram os primeiros casos judiciais sobre violação de correspondência, ou então o significativo fato de que a obra clássica de François Geny - De le secret sur les lettres missives - seja nada mais que um estudo encomendado pelo governo francês que visava a fornecer subsídios para a renovação e ampliação do sistema postal nacional ${ }^{251}$.

\section{DA POSSIBILIDADE DE CONTROLE SOCIAL PELA INTERNET}

Ao longo da história, os governos se esforçaram para manter o controle social; o avanço da técnica ocasionou seus maiores desafios de controle, a exemplo disso, tem-se o surgimento do telefone, do telégrafo, do rádio, cada qual à sua época. Atualmente o surgimento da internet. Todas essas invenções fizeram com que o poder de mando do Estado estenda seus braços para a regulamentação do uso desses instrumentos. Em parte a interferência do Estado como agente limitador da utilização em prol de convivência geral e harmônica é justificada, entretanto se têm vários exemplos históricos no que tange a exacerbação do controle social, a forma ilimitada de controle. É preciso ter olhos ávidos para identificar os resquícios do controle ilimitado, que desapercebidos chegam ao senso comum. Existe uma linha tênue entre a função do Estado protetor para o Estado limitador, a exemplo disso há a sociedade disciplinar e a sociedade de controle.

Há muito se tem tratado a ideia de sociedade disciplinar e sociedade de controle, consagradas nas obras de Michel Foucault e Gilles Deleuze. A contemporaneidade trouxe inúmeros desdobramentos em relação aos conceitos atribuídos por Foucault e Deleuze, sendo que muitos desses resultados foram previstos pela análise de acontecimentos por esses pensadores; entretanto continua-se em busca do entendimento da evolução das sociedades no que tange ao poder e a sua manutenção, ao direito, à ética e aos possíveis resultados sociais futuros. Faz-se necessário entender a dialeticidade desse tema para compreender o momento atual e pensar o futuro.

Na obra Vigiar e Punir ${ }^{252}$, Foucault trata da história da aplicação do direito

${ }^{250}$ Gibbon descreve o interessantíssimo sistema postal da Roma imperial - o cursus publicus - cuja utilidade para a manutenção do império não deve ser desprezada. As cartas eram transportadas por cavalos, que a levavam por aproximadamente 40 milhas romanas (cerca de $60 \mathrm{~km}$ ) até que atingissem uma espécie de "estação de retransmissão": uma repartição com outros cavalos que levariam ininterruptamente a mensagem até seu destinatário, em toda a extensão do império. O serviço, idealizado para uso militar, acabou sendo usado também pelos cidadãos romanos. Edward Gibbon. Declínio e queda do Império Romano. São Paulo: Companhia das Letras, 1989.

${ }^{251}$ François Geny. Des droits sur les lettres missives. Étudiés principalement en vue du système postal français. Paris: Sirey, 1911.

${ }^{252}$ FOUCAULT, Michel. Vigiar e punir: nascimento da prisão. 38. ed. Petrópolis: Vozes, 
penal. Da evolução dos suplícios (castigos corporais) às prisões atuais (restrições de liberdade), em que as mudanças nos paradigmas de punição do século XVI ao XVIII são analisadas. Em outras obras, fruto de aulas ministradas no College de France, como História da Sexualidade ${ }^{253}$ e Em Defesa da Sociedade ${ }^{254}$, Foucault mostrava os sinais de mudanças no exercício de poder e de sua manutenção. A biopolítica e o biopoder fazem parte de uma longa análise social foucaultiana, chegando à ideia de corpos dóceis e domesticados; também ao modelo panóptico das prisões, com um único observador/controlador para aqueles que ocasionaram a própria restrição de liberdade, geralmente por descumprir o modelo social imposto, ou seja, descumprir a vontade do soberano ou desafiar o poder de mando do Estado, isto é, a sociedade disciplinar. Ao identificar a mudança no paradigma penal, do punir para o vigiar, Foucault identificou os três componentes tidos como caracterizadores do objetivo do modelo panóptico de observação: a vigilância, o controle e a correção.

A partir da tríade do modelo de vigilância anteriormente referido, deu-se a inspiração para as formas de vigilância atuais, com um único observador que tudo vê, mas sem ser visto, de forma onipresente e onividente.

Para Deleuze, a sociedade de controle é uma espécie de evolução da "disciplina", para o que ele denomina como controle $^{255}$, por exemplo, na forma de exercício, em que a disciplina seria exercida em escolas, hospitais, forças armadas e outros; o poder por meio do controle seria exercido à distancia, de forma incorpórea e sem lugar especifico - virtualmente - de modo a estar presente com características de ubiquidade. A forma de vigilância e monitoração, mediante controle, deu origem a programas televisivos como o Big Brother - mundialmente posto em prática em que os telespectadores atuam como observadores do convívio de um grupo de pessoas, geralmente com perfis diferentes, apostando nas discordâncias de atitudes dos integrantes e no choque do convívio confinado, sob pressão interna e externa a pressão interna refere-se ao prêmio de participação pelo finalmente considerado Grande Irmão; e externa, pois a ideia de monitoração causa dependência nos observadores/telespectadores no sentido de necessidade ao acompanhar o desenrolar da convivência - o programa que é atrelado a um prêmio final, em dinheiro, evidencia a permissão do uso da privacidade dos participantes como fonte de audiência televisiva.

Neste sentido, outro exemplo atual da vigilância e monitoração, com a

2010. p. 291.

${ }^{253}$ FOUCAULT, Michel. História da sexualidade. Rio de Janeiro: Graal, 1985-2009. 3 v. (Biblioteca de filosofia e história das ciências), v.1.

${ }^{254}$ FOUCAULT, Michel. Em defesa da sociedade: curso no collège de france (1975-1976). São Paulo: Martins Fontes, 1999. xiv, 382 p. (Coleção tópicos).

255 "Não creio que os media tenham muitos recursos ou vocação para captar um acontecimento. Primeiro, eles mostram com frequência o começo e o fim, ao passo que um acontecimento, mesmo breve, mesmo instantâneo prolonga-se" (Deleuze: 1992, p. 198). 
crescente de violência em todos os setores, é que instituições públicas e privadas têm apostado no monitoramento por meio de câmeras de segurança, a partir do que se confirma o modelo de sociedade de controle, na dependência de um único observador onipresente e onividente em prol da segurança geral. Sob a máscara da segurança o poder ainda é exercido de forma incorpórea e quase oculto.

À luz dos marcos teóricos acima, o controle se estabelece pela ideia de necessidade relativamente ao veiculo de informação, em que a sociedade de controle é a sucessora do paradigma disciplinar (a disciplina já está incorporada). Para Deleuze, a vigilância e a monitoração são formas de atuação do controle, ou seja, a reinvenção do panóptico (ótico=ver + pan=tudo) de Jeremy Bentham, modelo de construção arquitetônica, que permite que um único observador acompanhe, por todos os lados, o que acontece nas celas prisionais.

As ramificações dessas formas de sociedade, atualmente, valem-se da internet e seu acesso facilitado para propagar-se ao maior contingente de pessoas possível, seja por meio de rede sociais, programas de reality-shows, inclusão de câmeras de vigilância, exatamente como referia-se George Orwell na obra $1984^{256}$, o poder pelo poder.

\section{AS REDES ROCIAIS E A WEB $\mathbf{2 . 0}$}

A internet, com o advento da denominada WEB 2.0, possibilitou a inserção nas redes sociais, que conectam o mundo, em que se tem acesso e interação com outras culturas, realidades, costumes, enfim, a tudo o que seja necessário e procurado por cada pessoa. Em termos de tecnologia, foi um avanço sem precedentes. No Brasil, um dos grandes exemplos de interação em redes sociais foi o ORKUT, que a princípio era uma página de recados em grupos específicos, em que se podia postar fotos, vídeos, participar de comunidades de áreas afins; podendo ser uma fonte usada para outras finalidades, como publicidade, além do que se possibilitava o risco de que alguém do outro lado da tela estivesse, com o acesso a essas informações, a utilizá-las para finalidades diversas, positivas ou negativas, inclusive contra o usuário que de boa-fé postava suas informações, fato que se estendeu às outras redes sociais que se multiplicaram desde então. A necessidade psicológica de inserção social faz com que os indivíduos divulguem informações confidenciais, correndo o sriscos em termos de segurança.

Estar conectado ao mundo virtual é uma tendência que cada vez mais se enraíza em nossa cultura e de forma tão profunda que as pessoas conscientemente divulgam informações que, a princípio, seriam confidenciais e as lançam à rede aberta, sem cogitarem a hipótese de que suas ações podem repercutir negativamente na esfera social, além de poderem ser chamarizes de crimes que venham a ser cometidos contra elas.

${ }^{256}$ ORWELL, George. 1984. São Paulo: Companhia das Letras, 2009. 


\section{OS EUA E O CONTROLE SOCIAL}

No inicio do mês de junho de 2013 o jornal britânico The Guardian revelou ao mundo que os Estados Unidos da América - EUA se utilizam de amplos programas secretos de monitoramento das comunicações telefônicas e digitais a fim de espionar informações de indivíduos e Estados. Há nessa prática evidente quebra de sigilo de acesso de usuários contidos em banco de dados de empresas virtuais renomadas como o Facebook, a Microsoft, o Google e outros. A informação teve como fonte o ex-consultor de inteligência da NSA, o norte-americano Edward Snowden.

Em 23 de agosto de 2013 foi divulgado, novamente pelo britânico The Guardian, o compartilhamento dos documentos secretos que comprovam as afirmações de Snowden com o jornal norte-americano The New York Times - NYT, sendo que o objetivo da parceria é continuar expondo a vigilância maciça dos governos envolvidos.

Posteriormente, em 27 de agosto de 2013, o Ministro da Justiça do Brasil, José Eduardo Cardozo, viajou para os Estados Unidos para analisar as denúncias de espionagem eletrônica contra brasileiros. No mesmo dia 27 a rede social Facebook, numa tentativa de transparência, divulgou uma lista em que constam as solicitações de informações de 38 mil usuários apenas nos seis primeiros meses do ano de 2013, destes $79 \%$ foram pedidos originários dos EUA.

Através do diretor do FBI, Robert Müller, o governo norte-americano afirmou que tomará as medidas cabíveis para processar Snowden pelo vazamento de informações secretas de programas de vigilância do País, afirmando ainda que o monitoramento é utilizado apenas para estrangeiros e que os programas utilizados foram aprovados por um juiz e estão de acordo com a Constituição norte-americana.

O governo norte-americano negou uma espécie de acordo com o governo brasileiro, tendo como objetivo determinar como seria a reciprocidade de concessão de dados pelos dois países. O objetivo geral da proposta era a possibilidade do país norte-americano solicitar aos tribunais brasileiros a quebra de sigilo de acesso da internet, sob o crivo da legislação brasileira, quando da suspeita de prática de ilícitos. A resposta negativa teve como justificativa a luta contra o terrorismo.

Após esse fato, foi divulgado que a presidente Dilma Roussef foi objeto de interceptações de dados da internet, inclusive com a sua rede de assessores.

O governo brasileiro solicitou justificativa desses atos contra a presidente, por escrito, e aguarda a resposta para tomar as medidas cabíveis, entre elas existe a possibilidade de recurso a Organização das Nações Unidas - ONU.

Caso sejam confirmadas as denúncias quanto a utilização de dados pessoais de civis, pelo governo dos Estados Unidos, torna-se premente a necessidade da proteção jurídica de dados disponíveis na internet e a construção de uma moral social de uso, posto que as informações concedidas voluntariamente pelos usuários da internet podem estar sendo usadas contra eles, nos termos explicitados anteriormente quanto ao tema da sociedade de controle. 


\section{Conclusão}

Para o direito, a crescente importância que assume a necessidade de proteção dos dados pessoais se traduz no fato de que uma considerável parcela das liberdades individuais hoje sejam exercidas concretamente por meio de estruturas nas quais a comunicação e a informação têm papel relevante.

As diversas formas de controle tornadas possíveis com a manipulação de dados pessoais devem ser levadas em consideração pelo operador do direito.

A partir da legislação atual existente é possível localizar um "núcleo comum" que caracteriza e que encontra expressão como um conjunto de princípios a ser aplicado na proteção de dados pessoais, sintetizados na Convenção de Strasbourg e nas Guidelines da OCDE, no início da década de oitenta. Pode-se, a esse respeito, elaborar uma síntese desses princípios ${ }^{257}$ :

1. Princípio da publicidade (ou da transparência), pelo qual a existência de um banco de dados com dados pessoais deve ser de conhecimento público, seja através da exigência de autorização prévia para funcionar, da notificação à uma autoridade sobre sua existência; ou do envio de relatórios periódicos;

2. Princípio da exatidão: Os dados armazenados devem ser fieis a realidade, o que compreende a necessidade de que sua coleta e seu tratamento sejam feitos com cuidado e correção, e de que sejam realizadas atualizações periódicas conforme a necessidade;

3. Princípio da finalidade, pelo qual qualquer utilização dos dados pessoais deve obedecer à finalidade comunicada ao interessado antes da coleta de seus dados. Este princípio possui grande relevância prática: com base nele fundamentase a restrição da transferência de dados pessoais a terceiros, além do que pode-se, a partir dele, estruturar-se um critério para valorar a razoabilidade da utilização de determinados dados para uma certa finalidade (fora da qual haveria abusividade) ${ }^{258}$;

4. Princípio do livre acesso, pelo qual o indivíduo tem acesso ao banco de dados em que suas informações estão armazenadas, podendo obter cópias desses registos, com a consequente possibilidade de controle desses dados; após este acesso e de acordo com o princípio da exatidão, as informações incorretas poderão ser corrigidas e aquelas obsoletas ou impertinentes poderão ser suprimidas, ou mesmo pode-se proceder a eventuais acréscimos;

\footnotetext{
${ }^{257}$ cf. Stefano Rodotà, op. cit.; p. 62. José Adércio L. Sampaio. op. cit., pp. 509 - ss.

${ }^{258}$ Ressalte-se que o princípio da finalidade foi mencionado em decisão do Superior Tribunal de Justiça referente a cadastros de crédito: "O Serviço de Proteção ao Crédito (SPC), instituído em diversas cidades pelas entidades de classe de comerciantes e lojistas, tem a finalidade de informar seus associados sobre a existência de débitos pendentes por comprador que pretenda obter novo financiamento. É evidente o benefício que dele decorre em favor da agilidade e da segurança das operações comerciais, assim como não se pode negar ao vendedor o direito de informar-se sobre o crédito do seu cliente na praça, e de repartir com os demais os dados que sobre ele dispõe.
} 
5. Princípio da segurança física e lógica, pelo qual os dados devem ser protegidos contra os riscos de seu extravio, destruição, modificação, transmissão ou acesso não autorizado.

Esses princípios, mesmo que fracionados, condensados ou adaptados, podem ser identificados em diversas leis, tratados e convenções. Eles são o núcleo das questões com as quais todo ordenamento se deve deparar ao procurar fornecer sua própria solução ao problema da proteção dos dados pessoais.

\section{REFERÊNCIAS}

AGRE, Phillip, ROTENBERG, Marc. Technology and privacy: the new landscape. Cambridge: MIT Press, 1997.

ALPA, Guido. Privacy e statuto dell'informazione. In: Banche dati telematica e diritti della persona.

AMARAL, Francisco. O direito civil na pós-modernidade. In: Revista Brasileira de Direito Comparado, n. 21, 2002.

BALDASSARRE, Antonio. Privacy e costituizione. l'esperienza statunitense. Roma: Bulzoni, 1974.

BARRETTO, Vicente. Problemas e perspectivas da bioética. In: Bioética no Brasil. RIOS, André (Org.) et al, Rio de Janeiro: Espaço e Tempo, 1999.

BAUMAN, Zygmunt. La società individualizzata. Bologna: Il Mulino, 2001.

BECKER, Laércio. O direito na escola de frankfurt: balanço de uma desconfiança. In: www2.uerj.br/ direito/publicacoes/mais_artigos/o_direito_frankfurt.html (02/01/2004).

BELL, Daniel. The coming of post-industrial society. New York: Basic Books, 1999.

BENNETT, Colin. Regulating privacy, data protection and public policy in europe and the united states. Ithaca: Cornell University Press, 1992.

BENTHAM, Jeremy. Teoria das penas legais. Campinas: Bookseller, 2002.

BENTHAM, Jeremy, MILL, John Stuart. Uma introdução aos princípios da moral e da legislação. São Paulo: Nova Cultural, 1989.

BLACKSTONE, William. Commentaries on the laws of england. Oxford: Clarendon Press, 1765-1769.

BLOUSTEIN, Edward. Privacy as an aspect of human dignity: an answer to dean prosser. In: 39 New York University Law Review 962 (1964).

BURKERT, Herbert. Privacy-data protection: a german/european perspective. In: Governance of Global Networks in the Light of Differing Local Values. 
CAIRNCROSS, Frances. The death of distance. Boston: Harvard Press, 1997.

CARRINO, Agostino. Progresso e modernità. In: Il diritto nella società moderna. Napoli: ESI, 1995.

CARVALHO, Luis Gustavo Grandinetti de. Direito de informação e liberdade de expressão. Rio de Janeiro: Renovar, 1999.

CASTELLS, Manoel. The rise of the network society. Blackwell: Oxford, 1996 [ed. bras.: A sociedade em rede. Rio de Janeiro: Paz e Terra, 1999].

CATALA, Pierre. Ebauche d'une théorie juridique de l'information. In: Informatica e Diritto, ano IX, jan-apr. 1983.

CELLA, José Renato Gaziero, VAZ, Ana Carolina. The prohibition of the right to anonymity on the autthoritarian brazilian constitucion ant its impact on social networks. In: XXV World Congress of Philosophy of Law and Social Philosophy - Law, Science, Technology, 2011, Frankfurt am Main. Abstract Book. Frankfurt am Main: Normative Orders - Exzellenzcluster an der Goethe-Universität, 2011. p. 346-347.

COMPARATO, Fabio Konder. A democratização dos meios de comunicação de massa. In: Dossiê Comunicação, nº 48, dez./2000-fev./2001.

CONDORCET, Jean-Antoine-Nicolas de Caritat (marquis de). Esquisse d'un tableau historique des progrès de l'esprit humain. Paris: Masson \& fils, 1822 [ed. bras.: Esboço de um quadro histórico dos progressos do espírito humano. Campinas: Unicamp, 1993].

DELEUZE, Gilles. Conversações: 1972-1990. Rio de Janeiro: Ed. 34, 1992. . Foucault. Lisboa: Vega, 1987.

. A imagem-movimento: cinema. 2. ed. Lisboa: Assírio \& Alvim, 2009. . A imagem-tempo. São Paulo: Brasiliense, 1990.

DELEUZE, Gilles, GUATTARI, Félix. O que é a filosofia? 2. ed. São Paulo: Ed. 34, 1997.

DENNINGER, Erhard. Tutela ed attuazione del diritto nell'età tecnologica. In: Nuovi diritti dell'età tecnologica, cit.,.

DUBY, Georges, ARIÈS, Phillipe. La vita private: dal feudalesimo al rinascmento. Bari: Laterza, 2001.

ECO, Umberto. Sei passeggiate nei boschi narrativi. Minalo: Bompiani, 1994.

FACHIN, Luiz Edson. Discriminação por motivos genéticos. In: Revista da Faculdade de Direito da UFPR, v. 36, 2001.

FACHIN, Luiz Edson, RUZYK, Carlos Eduardo. Direitos fundamentais, dignidade 
da pessoa humana e o novo código civil: uma análise crítica. In: Constituição, direitos fundamentais e direito privado. SARLET, Ingo Wolfgang (Org.), cit., .

FOUCAULT, Michel. Em defesa da sociedade: curso no collège de france (19751976). São Paulo: Martins Fontes, 1999.

. História da sexualidade. Rio de Janeiro: Graal, 1985-2009.

. Vigiar e punir: nascimento da prisão. 38. ed. Petrópolis: Vozes, 2010.

ORWELL, George. 1984. São Paulo: Companhia das Letras, 2009. 